\title{
Evaluation of Mechanical properties for polypropylene Modified Asphalt concrete Mixtures
}

\author{
Safaa Moubark $^{1}$, Farag Khodary ${ }^{2}$, Ayman Othman ${ }^{3}$ \\ ${ }^{1}$ Civil Engineer at the General Authority for Roads and Bridges Red Sea - Egypt \\ ${ }^{2}$ Civil Engineering Department, Faculty of Engineering, South Valley University \\ 3Civil Engineering Department Faculty of Engineering, Aswan University
}

\begin{abstract}
:
It is noticeable that the increase of road traffic during the last two decades in addition to the insufficient degree of maintenance caused an accelerated deterioration of road structure. These roads show early signs of distress such as rutting, cracking, low temperature cracking, ageing and stripping. Heavier loads and higher traffic volume demand higher performance of pavement. Excellent performance of pavement requires bitumen that is less susceptible to high temperature, rutting or low temperature cracking. Several additives are used to increase the performance of bitumen and the quality of the produced mixtures. Polymers are considered the most widely used additives in asphalt modification that give better performance. The performance of the Polymer-modified asphalt depends on the type and the level of modification the used polymer. The choice of modification level and modification type depends on the physical properties of the polymer, and its compatibility with bitumen. The polymer can be loosely classified into two categories, Plastomers and Elastomers. The results indicated that, the addition of polypropylene generally improved the mechanical properties of the mixture regardless of the percentage of polymers that added and (PP) content of 5\%. it can be noticed that the performance of PP-modified asphalt mixtures is better compared with unmodified asphalt concrete mixtures modifier because it has the highest Marshall Stiffness, indirect tensile strength and unconfined compressive strength .
\end{abstract}

Keywords: asphalt concrete, polymer, Marshall Stiffness, compressive strength, Indirect Tensile Strength

\section{Introduction}

The Egyptian Government invested a huge sum of money in the field of highway construction to reach excellent pavement performance. However, these roads show early signs of distress such as rutting and Fatigue cracking [4]. There are two principal solutions to construct durable pavement; firstly, applying a thicker asphalt pavement which will increase the construction cost, secondly, making an asphalt mixture with modified characteristics [2]. by using additives such as polymers. Polymers can improve the properties of the mixture, because it offers the possibility to produce mixtures that can resist both rutting and cracking. Bitumen is one of the two principal constituents of asphalt concrete mixtures, it is a dark brown to black cementinious material that is either naturally occurring or is produced by the distillation of crude oil [8]. In the context of asphalt pavements, there aree bitumen characteristics which are considered very important to the performance of the pavement in service. These characteristics are: temperature susceptibility, viscoelasticity, and aging [8]. Bitumen behavior is also dependent on time of loading. The same load applied for different durations will result in different behaviors for the same asphalt. The dependency of the bitumen on both the temperature and time of loading makes it possible to use these factors interchangeably. In other words, a slow loading rate can be simulated by high temperatures and a fast loading rate can be simulated by low temperatures (Roberts et .al.1996).

Chemically, bitumen is composed of organic molecules (hydrocarbon) and therefore reacts with oxygen. The result of this reaction is called aging. Aging is the hardening of the bitumen as it reacts with oxygen to the extent that it becomes brittle [1]. Pavements with aged asphalt are more susceptible to cracking that will ultimately lead to structural or functional failure of the pavement.

Asphalt pavement distresses are categorized into three main types cracking, surface deformation, and surface defects. There are many reasons for 
asphalt concrete damage such as mixture disintegration, fracture and Viscoplastic flow. Fatigue cracking is one of the main modes of asphalt pavement deterioration caused by traffic and environmental factors. This type of cracking is also known as "alligator cracking" [7].The initial stages of fatigue cracking can be recognized by the presence of periodic longitudinal wheel path cracks, where the cracks occurring in the direction of traffic. The cracks occupy a small area initially but gradually propagate and cause large cracks due to more loading being applied to the pavement Permanent deformation or rutting is one of the main problems in Asphalt concrete pavements and is usually defined as: developing of longitudinal deformation (depression) under the action of repeated wheel path [6]. and it can be defined as when a cross section of the pavement is no longer in its design position, it is called by "Permanent" deformation name because it shows an accumulation of small amount of depression (deformation, strain) which occurs under the repeated load of vehicles wheel path [3]. Using polymer depends on many factors such as cost, construction ability, availability, and expected performance. In this current proposal, we will discuss the useful application of polymer as asphalt modifier to be used in a mixture with bitumen in road pavement. The principal objectives of this research are to study the effect of polymer type, structure and content on the properties of modified asphalt concrete mixtures. The research outcomes are expected to be fundamental bases for improving asphalt concrete mixtures properties. The research objectives are organized as follows:

- To study the effect of polymer type on asphalt modification

- To obtain softer blends that can reduce cracking

- To reach stiffer blends at high temperatures and reduce Rutting

- To increase the stability and the strength of mixtures

- To improve fracture resistance of blends

\section{Theoretical approach}

\subsection{Marshall Stiffness}

The mechanistic evaluation included Marshall Stiffness and compressive strength and Indirect Tensile Strength asphalt concrete mixture. Marshall Stiffness (MS) is widely used to characterize the mechanical performance of asphalt concrete mixtures. It is considered combined index that reflects both stability and plastic flow characteristic of the mixture [5]. It is obtained from marshal stability test using the following equation (1).

$$
\mathrm{MS}=\frac{\mathrm{Si}}{\mathrm{Fi} \mathrm{xb}}
$$

Where:

MS = marshal stiffness

$\mathrm{Si}=$ Mixture's stability at bitumen content (i)

$\mathrm{Fi}=$ Mixture's flow at the same bitumen content (i)

$\mathrm{b}=$ sample thickness

\subsection{Compressive strength}

Compressive Strength is the maximum compressive stress that a material is capable of withstanding without fracture. The compressive strength of the mixtures can be obtained through applying a compression load on the circular face of a circular specimen. The load is increased until failure occurs. The compressive strength can be calculated using the following equation (2).

$$
\sigma_{\mathrm{c}}=\frac{4 \mathrm{P}_{\max }}{\pi \mathrm{D}^{2}}
$$

Where $\sigma c$ is the unconfined compressive strength, $\mathrm{P}$ max is the Maximum applied compressive load and, $\mathrm{D}$ is the diameter of the specimen.

\subsection{The indirect tensile stress}

Indirect tensile strength test According to (ASTM D 4123) is used to determine the tensile Strength of mixtures. The indirect tensile test was devolved for testing cylindrical concrete specimens through the application of a compression load along a diametrical plan through two opposite loading heads. This test involves loading a cylindrical specimen with a compressive load along two opposite generators. This results in a relatively uniform tensile stress acting perpendicular to and along the diameter plan of applied load. The specimen failed by splitting along the vertical diameter as shown in Figure (3.6). Indirect tensile strength was computed as follows equation (3.3).

ITS $=\frac{2 \mathrm{P}}{\pi \mathrm{Dt}}$

Where:

$\mathrm{P}=$ the peak load, $\mathrm{KN}$

$\mathrm{D}=$ specimen diameter, $\mathrm{cm}$

$\mathrm{T}=$ specimen thickness, $\mathrm{cm}$

\section{Materials and Methods}

\subsection{Aggregates}

Sieve analysis was performed on crushed limestone aggregates on accordance to Egyptian highway standard specifications. Gradation of aggregates obtained from sieve to achieve the required gradations $23 \%$ of coarse aggregate (a) 
was blended with $36 \%$ of coarse aggregate (b) and $36 \%$ of sand these were blended together. The selected gradations of aggregate used in all asphalt concrete mixtures meet the Egyptian highway standard specifications.

\subsection{Bituminous Material}

Asphalt of 60/70 penetration grade was used in this study. This asphalt was obtained from Suez refinery. The physical properties of this bitumen are given in Table (1) including penetration, softening point and specific gravity.

Table 1: Physical Properties of Used Bitumen

\begin{tabular}{|c|c|c|}
\hline Property & Value & Specifications \\
\hline Penetration & 65 & $60-70$ \\
\hline softening point & 52.2 & $45-55$ \\
\hline Specific gravity & 1.02 & $1-1.1$ \\
\hline
\end{tabular}

\subsection{Polymers}

\subsubsection{Polypropylene}

Polypropylene (PP), which is one of the most popular polymers. It serves double duties, both as a plastic and as a fiber. These materials have good plastic properties. The physical and chemical properties of PP are shown in table (2).

Table 2: physical and chemical properties of P.P

\begin{tabular}{|c|c|}
\hline Physical state & Pellets or granules \\
\hline Co lour & White \\
\hline Melting point & $170-176$ \\
\hline Density & $0.89 \mathrm{~g} / \mathrm{cm} 3$ \\
\hline
\end{tabular}

\section{Asphalt Concrete Mixture Design}

The design of asphalt concrete mixtures used in this study was based on Marshall Mix design method, described in AASHTO. This method was used to determine the optimum bitumen content (OBC) for mix design. Marshall Specimen was prepared by adding bitumen (4, 4.5, 5.0, 5.5 and $6.0 \%$ by weight of aggregate. Then, density, Marshall Stability, flow and volumetric properties [air voids and voids filled with bitumen (VFB),] were determined the optimum bitumen content.

\subsection{Sample Preparations}

The coarse aggregate, fine aggregate, and the filler material should be proportioned so as to fulfill the requirements of the standards. The required quantity of the mix is taken so as to produce compacted bituminous mix specimens of thickness $63.5 \mathrm{~mm}$ approximately. $1200 \mathrm{gm}$ of aggregates and filler are required to produce the desired thickness. the aggregates are heated to temperature of $170^{\circ} \mathrm{c}$ to $190^{\circ} \mathrm{C}$.The used polymers additives were blended with the bitumen at temperatures of about $170^{\circ} \mathrm{C}$. mixing equipments and specimen molds were also placed in the oven at the same temperature (i.e. $170^{\circ} \mathrm{C}$ ) for one hour prior to the mixing operation. The heated aggregate was placed into the mixer immediately after that the heated bitumen is added to the aggregate blend. The mix is placed in a mould and compacted with 50 blows on each side of the specimen. Then the sample was taken out of the mould after cooling to room temperature and the sample was extracted from the mould then placed with other samples to maintain the same conditions.

\section{Results and Discussion}

\subsection{Effect of polypropylene content on Marshal Stiffness}

The values of Marshal stiffness for P.P modified mixtures were calculated based on Equation (1) and presented Figure (1) present the value of Marshal stiffness for control mixture and 5,7\% of P.P added in mixture. figure (2) it can be noticed that, Marshal stiffness for mixtures modified with P.P is higher than control mixtures, while mixtures modified with $5 \%$ pf P.P is higher than mixtures modified with $7 \%$ P.P . it can be seen that ,the adding of P.P enhanced the results of MS as compared to the control mixtures. Modified with 5\% P.P is higher stiffness mixture than $7 \%$ P.P content because of $5 \%$ P.P is higher stability than $7 \%$ P.P and also the flow value for 5\% P.P is lower than value of 7\% P.P. 


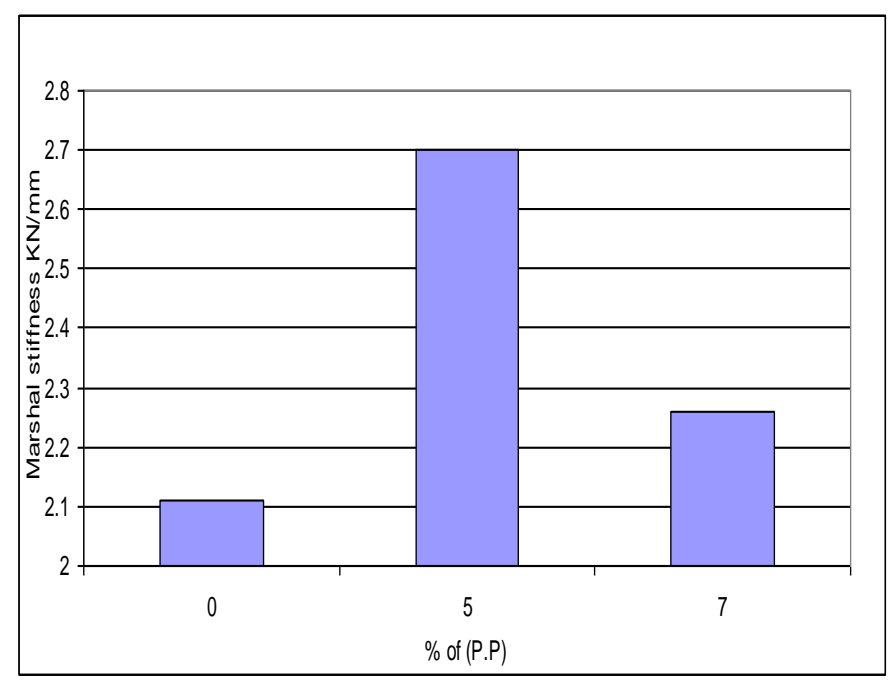

Figure 1: Relationships between Marshall Stability and $\%$ of modifier content

\subsection{Effect of polypropylene content on} Compressive test

Values of Compressive strength for modified and unmodified asphalt concrete mixtures are calculated based on equation (2) and presented in Figure (2). With Different Percentages of Polypropylene From the results in Figure (4 ) it can be seen that the compressive strength of mixture modified with PP additive increased with a increase of PP content, This may be related to a reduction in air voids content of the modified

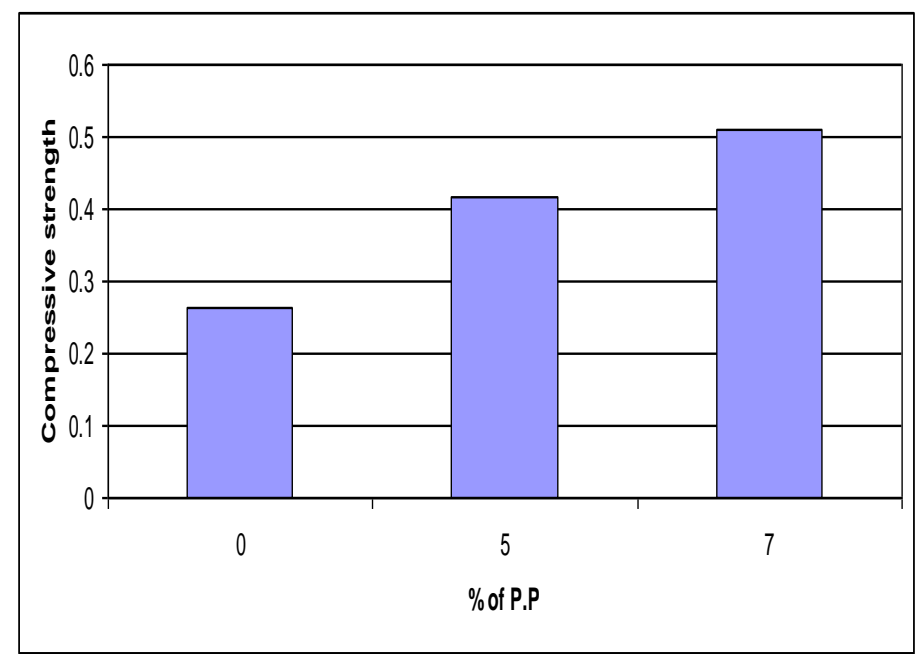

Figure 2: Compressive Strength for polypropylene modified asphalt concrete mixtures

\subsection{Effect of polypropylene content on indirect strength}

The values of Indirect Tensile Strength (ITS) for both control mixture and mixtures modified with Polypropylene added in various content at $25^{\circ} \mathrm{C}$ were calculated according to Equation (3), and Figure (3) presents the mean of indirect tensile strength results. ITS for mixtures modified with Polypropylene improve the indirect strength of mixture because the viscosity of P.P-modified asphalt is higher than that of conventional asphalt, and 5\% P.P has the highest value of indirect tensile strength than modified asphalt concrete mixtures with $7 \%$ P.P and control mixture.

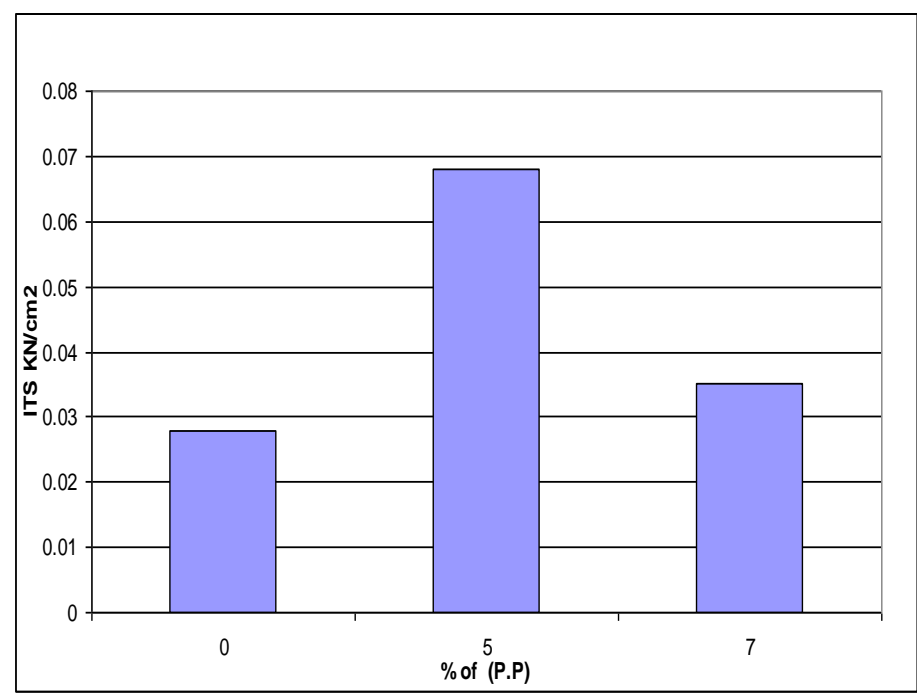

Figure 3: Relation between P.P content and Indirect Tensile strength

\subsection{Title and authors}

\section{Conclusion}

The main objectives of this research were to study the mechanical performance of polypropylene modified asphalt concrete mixtures. The additions of modifier to the pure bitumen improve the properties of bitumen. Mechanistic and simulative tests were conducted in modified and unmodified asphalt concrete mixtures, Indirect Tensile Strength and Compressive test and Marshall Stiffness test After conducting laboratory tests on bitumen and mixtures with polymers content and after analyzing the data and comparing the results, the following conclusions have been drawn:

- The polymer modification has enhanced physical properties of bitumen mixture.

- Adding (P.P) content showed increases the stability and the flow decreases up to $5 \%$ P.P content.

- The effect of additive on increasing the indirect tensile strength value of mixture is more influential in the conditioned state due to the improved adhesion property.

- The value of Compressive strength for $7 \%$ modified asphalt concrete mixtures with ( $\mathrm{P}$. $\mathrm{P})$ has the heights value comparing with the value of Compressive strength for $0 \%$ and 5 $\%$ asphalt concrete mixtures.

\section{References}

1. Alvarez C.; Thompson M. R. "Aging Phenomenon in Asphalt Concrete Pavements- 
ALiterature Review". Supplemental Report Project 1A-A1 FY 92, Illinois Transportation Research Center, Illinois Department of Transportation, December 1994.

2. Arabani, M., Mirabdolazimi, S.M., and Sasani, A.R. (2010). "The Effect of Waste Tire Thread Mesh on the Dynamic Behavior of Asphalt Mixtures", Construction and Building Materials, Vol. 24, 2010, pp. 10601068.

3. Druta, C. (2006). A micromechanical approach for predicting the complex shear modulus and accumulated shear strain of asphalt mixtures from binder and mastics. louisiana: Louisiana State University.

4. F. Khodary, Ph.D. Thesis "Evaluation of Fatigue Resistance for Modified Asphalt Concrete Mixtures Based on Dissipated Energy Concept" Department of Civil Engineering and Geodesy Technische Universität Darmstadt, March 2010.

5. Hozayen, A.H., and Othman, A. (2008). "Improving Mechanical Properties of Asphalt Concrete Mixtures Using Thermoplastic Polymer Additives", a Paper Presented at Gulf Conference on Transportation ", Dubai, UAE.

6. Kandhal, P.S., Mallick, R.B., Brown, E.R. (1998). Hot mix asphalt for intersections in hot climates. Auburn: national center for asphalt technology.

7. McGennis, B.R, Anderson, R.M. , Kennedy, T.W., and Solaimanian,M. (1995). "Background of Superpave Asphalt Mixture

8. Roberts Freddy L.; Mohammad Louay N.; Wang L. B. "History of Hot Mix Asphalt Mixture Design in the United States". 150th Anniversary Paper, American Society of Civil Engineers, Journal of Materials in Civil Engineering, Vol. 14, No. 4 August 2002. 